\title{
A propósito de un edificio en el Barrio Cívico de Santiago de Chile: La Ex Caja de Crédito Agrario.
}

A building in the Civic Center in Santiago, Chile: Former Caja Agraria

M. Isabel Pavez R. - Antonio Sahady V.

\section{Filiación}

Académicos de la Facultad de Arquitectura y Urbanismo de la Universidad de Chile.

\section{Palabras Clave}

Barrio cívico de Santiago de Chile, René Aranguiz Saravia, Luis Muñoz Maluschka, arquitectura moderna en Santiago de Chile.

\section{Resumen}

Se indaga en uno de los edificios del Barrio Cívico de Santiago de Chile, obra de los arquitectos René Aránguiz Saravia y Luis Muñoz Maluschka. Este último contribuyó al Barrio Cívico no sólo para efectos del mejor cumplimiento de las ideas de Karl Brunner y Carlos Vera, en su calidad de Jefe de la Sección de Urbanismo de la D.G.O.P., sino también desde algunas obras de arquitectura integrada al megaproyecto de diseño urbano del Barrio Cívico en los años 1930.

\section{Abstract}

It explores one of the buildings of the civic district of Santiago de Chile, by architects René Aránguiz Saravia, Luis Munoz and Maluschka. The latter contributed to the Civic Center not only for the purpose of better implementation of the ideas of Karl Brunner and Carlos Vera, in his capacity as Chief of the Section of Urbanism DGOP but also from some works of architecture built into the mega urban design the Civic Center in 1930.

\section{Key words}

Santiago civic center - Chile, René Aránguiz Saravia, Luis Muñoz Maluschka, Modern Architecture in Santiago - Chile.

\section{Sumario}

Introducción

La arquitectura del Barrio Cívico de Santiago

El edificio de la ex Caja de Crédito Agrario

Galería fotográfica

Figura 1.- Vista de la fachada principal del edificio de la ex Caja de Crédito Agrario, 1940.

Figura 2.- Vista de fachada interior del edificio de la ex Caja de Crédito Agrario, 1940. 
http://revistaurbanismo.uchile.cl

Figura 3.- Vista interior hacia niveles superiores de escalera del edificio de la ex Caja de Crédito Agrario, 1940.

Figura 4.- Vista interior hacia niveles superiores de escalera del edificio de la ex Caja de Crédito Agrario, 1940.

Figura 5.- Vista de área de trabajo junto a circulación en pisos superiores, con efecto de balcón sobre hall central del edificio de la ex Caja de Crédito Agrario, 1940.

Figura 6.- Salón de reuniones en el edificio de la ex Caja de Crédito Agrario, 1940.

Figura 7.- Detalle del hall central realzado por la luz cenital de lucernario del edificio de la ex Caja de Crédito Agrario.

Figura 8.- Geometrización de inspiración Art Deco, del arranque del pasa mano de la escala del edificio de la ex Caja de Crédito Agrario, 1940.

Figura 9.- Lucernario del edificio de la ex Caja de Crédito Agrario, 1940.

Figura 10.- Sala de estar del edificio de la ex Caja de Crédito Agrario, 1940.

Figura 11.- Vista actual del lucernario del hall central del edificio de la ex Caja de Crédito Agrario.

Figura 12.- Vista actual del lucernario del hall central del edificio de la ex Caja de Crédito Agrario, desde el piso superior.

Figura 13.- Vista actual de zonas de trabajo en diversos pisos, donde se aprecia ocupación de áreas de circulación originales, y cerramiento del espacio en el plano perimetral del hall central. Edificio de la ex Caja de Crédito Agrario.

Figura 14.- Vista actual de cielos y lucernarios desde el hall central del edificio de la ex Caja de Crédito Agrario.

Figura 15.- Vista del vacío central de escalera principal del edificio de la ex Caja de Crédito Agrario.

Figura16.- Vista de columna junto a escalera del edificio de la ex Caja de Crédito Agrario.

Figura 17.- Iluminación natural en escalera. Edificio de la ex Caja de Crédito Agrario.

Figura 18.- Vista hacia el sur oriente del Barrio Cívico desde la terraza del edificio de la ex Caja de Crédito Agrario.

Figura 19.- Vista hacia el nor-oriente del Barrio Cívico, sobre el Palacio de Gobierno, La Moneda, desde la terraza del edificio de la ex Caja de Crédito Agrario.

Figura 20.- Vista del edificio del la ex Caja de Crédito Agrario, en el conjunto norponiente del Barrio Cívico. El edificio de los arquitectos Muñoz y Aránguiz, corresponde al tercio central del bloque en la imagen.

Bibliografía

Anexo: "La altura de los edificios" [1930]. 


\section{Introducción}

El proyecto instaurador del Barrio Cívico de Santiago, un proyecto de Karl Brunner a partir de anteriores proposiciones (C. Carvajal; Smith Solar y Smith Miller, "Proyecto de Centro Cívico de la Capital") ${ }^{1}$ y ajustado por Carlos Vera Mandujano, fue aprobado oficialmente en 1937, aunque su construcción ya había comenzado hacía algún tiempo.

\section{Señala Figueroa ${ }^{2}$ :}

En la práctica Brunner considera de mayor relevancia los resultados y equilibrios alcanzados por las transformaciones en los nuevos escenarios resultantes, que los propios signos formales aislados que surgen por estas actuaciones. Nunca encontraremos en Brunner una propuesta asentada en una intervención traumática, haciendo tabla rasa de lo existente, al estilo de las que por aquellos mismos años postulaban los planes redactados por algunos representantes del Movimiento Moderno. Tampoco observaremos en su obra el sentido terminalista que es posible encontrar en la urbanística francesa de ultramar, más interesada en occidentalizar la ciudad colonial que en prestar atención a los elementos culturales propios del lugar.

Estrecha afinidad se encuentra, sin duda, en los planteamientos de la contraparte de Brunner en Chile, representada por el Jefe de la Sección de Urbanismo, Luis Muñoz Maluschka, entre 1936 y 1953. Muñoz hizo su contribución al Barrio Cívico, no sólo para efectos del mejor cumplimiento de las ideas de Karl Brunner y Carlos Vera, sino también desde algunas obras de arquitectura. Para el caso del edificio de la ex Caja de Crédito Agrario que se presenta más adelante, trabajó con el arquitecto René Aránguiz Saravia.

El pensamiento de Muñoz Maluschka formó parte de lo que se podría llamar un "racionalismo moderado" (interlocutores: Werner Hegemann, Karl Brunner, Stephan Prager), donde la base geográfica, social, y económica local para la Arquitectura y la Planificación Urbana era insoslayable, y tuvo gran afinidad también con lo que se podría llamar un "culturalismo no romántico" francés (figuras de afinidad: Gaston Bardet, Robert Auzelle), encontrándose también afinidad con los grupos "modernos moderados" ingleses. No es de extrañar por tanto que en su confrontación (a partir un conjunto relevante de escritos de L.M.M.) con los postulados del Movimiento Moderno en Urbanismo se encuentre oposición respecto de los puntos $15,16,17,27,29,35,62,82,92$ y 94, de un total de $95^{3}$ puntos precisados en la Carta de Atenas.

Podría parecer poco esta cifra de oposiciones, si su contenido no tocara ponencias fundamentales de la forma de hacer Arquitectura y Urbanismo del Movimiento Moderno.

GUROVICH, 2003.

FIGUEROA SALAS, Jonás, 1996, p. 6.

No todos ellos principios doctrinarios propiamente tales. 
A propósito de un edificio en el Barrio Cívico de Santiago de Chile:

La Ex Caja de Crédito Agrario.
A building in the Civic Center in Santiago, Chile: Former Caja Agraria

$\underset{I S S N \text { REVIST-5051 }}{\text { REV DE }}$

http://revistaurbanismo.uchile.cl

En efecto, el cuadro de confrontación que presentamos a continuación da una idea de lo señalado ${ }^{4}$ :

\begin{tabular}{|c|c|}
\hline & VARIANTES EN L. MUÑOZ M. RESPECTO DE LA CARTA DE ATENAS \\
\hline C.A. 15 & Zonificación estricta con uso de suelo exclusivo. \\
\hline Variante & $\begin{array}{l}\text { Mixtura de usos compatibles con la vivienda toda vez que fuera posible, para una mayor } \\
\text { animación y autocontrol de la ciudad. }\end{array}$ \\
\hline C.A. $16-62$ & $\begin{array}{l}\text { Vías de recorrido lento para uso exclusivo de los peatones y vías de recorrido rápido para } \\
\text { uso exclusivo los vehículos. }\end{array}$ \\
\hline Variante & No se promueve la separación de peatones y vehículos. Rechazo a las diagonales. \\
\hline C.A. 17 & Rechazo al alineamiento de viviendas al borde de las calles. \\
\hline Variante & $\begin{array}{l}\text { Diversidad de expresiones de la vivienda: en banda continua y altura media para aumentar } \\
\text { la densidad de población de áreas residenciales; adecuada a cada región geográfica; } \\
\text { adecuada a la diversidad de hogares, adecuada a cada grupo humano. }\end{array}$ \\
\hline C.A. 27 & $\begin{array}{l}\text { Debe prohibirse la alineación de las viviendas a lo largo de las vías [mayores] de } \\
\text { comunicación. }\end{array}$ \\
\hline Variante & $\begin{array}{l}\text { La diversidad de jerarquía de las vías no impide diseño de perfiles apropiados (Vías de } \\
\text { servicio a la vivienda). }\end{array}$ \\
\hline C.A. 35 & $\begin{array}{l}\text { Rechazo a las ciudades-jardín, las superficies verdes no estarán compartimentadas en } \\
\text { pequeños elementos de uso privado. Espacios verdes comunes continuos junto a la } \\
\text { vivienda en altura. }\end{array}$ \\
\hline Variante & $\begin{array}{l}\text { Rechazo de los espacios verdes indiferenciados. Se promueve diversidad de tipos de } \\
\text { espacios verdes, incluidas las pequeñas áreas privadas; énfasis en los parques de barrio ( } 6 \\
\text { Hás). }\end{array}$ \\
\hline C.A. 82 & $\begin{array}{l}\text { El urbanismo es una ciencia de tres dimensiones. Con la intervención del elemento altura } \\
\text { se dará solución a la circulación moderna y al esparcimiento mediante la explotación de los } \\
\text { espacios libres así creados. }\end{array}$ \\
\hline Variante & $\begin{array}{l}\text { El urbanismo es una ciencia de cuatro dimensiones. Es conveniente hacer ahorros } \\
\text { dirigiendo las demandas de uso también hacia el eje del tiempo y no sólo al del espacio. }\end{array}$ \\
\hline C.A. 92 & La arquitectura es responsable del bienestar y de la belleza de la ciudad. \\
\hline Variante & $\begin{array}{l}\text { La construcción de la ciudad debe referirse en primer lugar a un proyecto de Planificación } \\
\text { Urbana y Territorial con bases geográfica, económica y social; contar con él fue } \\
\text { considerado un derecho social. }\end{array}$ \\
\hline C.A. 94 & Movilización general del suelo urbano. \\
\hline Variante & Movilización del suelo urbano en forma selectiva, en estricto beneficio del interés colectivo. \\
\hline
\end{tabular}

Aún cuando la Carta de Atenas -redactada en 1933, publicada en Europa en 1942- fue publicada en Chile en 1946, nuestros profesionales nativos conocían sus planteamientos, y tuvieron ocasión de expresar sus posturas, aún antes de la redacción de este documento.

En efecto, observamos en un anteproyecto de "Plano Oficial" por mandato de la Comuna de Santiago, realizado por un equipo de arquitectos e ingenieros que incluyó a Luis Muñoz, en $1932^{5}$, que en la escala de la ciudad se rechazó toda "fantasía costosa", aprovechando al máximo el espacio público existente "mejorándolo en lugar de trastornarlo",

4 Este documento redactado en 1933, y publicado en Europa en 1942, fue publicado en Chile, en 1946, aunque los postulados se iban conociendo desde los CIAM.

5 MARDONES OTAÍZA, 1934.

Revista de Urbanismo N9 - Marzo de 2004 
A propósito de un edificio en el Barrio Cívico de Santiago de Chile:

La Ex Caja de Crédito Agrario.
A building in the Civic Center in Santiago, Chile: Former Caja Agraria

REVISTA DE

http://revistaurbanismo.uchile.cl

conservando con ello "el carácter propio de la ciudad". Las vías urbanas mayores se obtendrían por medio de ensanche en el damero central; en las nuevas zonas de poblamiento se restringiría al mínimo la apertura de ejes transversales a las vías fundamentales. Junto con rechazarse las vías diagonales -tal como lo había hecho Jacques Lambert en su informe para Santiago en 1929-30-, se promovía construir avenidaspaseo; la idea del cobro de la plusvalía a los propietarios beneficiados con las obras públicas -hasta un $50 \%$ - fue parte de estas proposiciones.

En la escala seccional, se observó que las vías tradicionales en torno a las manzanas del modelo clásico hispanoamericano contribuían a la animación y al éxito comercial, por lo cual se rechazó la idea de separar las circulaciones peatonales de las vehiculares; esto no impediría abrir pasos peatonales por el interior de las manzanas. En el mismo objetivo de animación de la ciudad se abogó porque las zonificaciones comprendieran usos mixtos compatibles con la residencia "toda vez que fuera posible".

En áreas de 4 o 5 pisos se establecería estacionamientos de vehículos en puntos estratégicos. Estos barrios tendrían parques verdes (6-10 Hás.) para mejorar el microclima local, y facilitar el juego de niños y adultos al abrigo de flujos intensos de vehículos. Coincidiendo con Lambert, el equipo de Muñoz rechazó la "moda de liberar grandes superficies verdes [indiferenciadas]", viendo además la conveniencia de contar con micro espacios verdes privados junto a la vivienda.

La elevación de la densidad residencial podría darse también mediante vivienda organizada en bandas edificadas continuas al borde de las calles, lo que no impediría la existencia de algunas zonas urbanas tipo "ciudad-jardín". Para Muñoz fue especialmente importante reconocer y atender a la gran diversidad de grupos sociales y modos de vida coexistiendo en las ciudades y regiones del país, por lo cual rechazó la estandarización de la vivienda.

\section{La arquitectura del Barrio Cívico de Santiago}

En el caso de la arquitectura del Barrio Cívico de Santiago, donde se contempló funciones administrativas del Estado tanto como uso residencial, el diseño de los edificios que estructuraron el espacio urbano fue escrupulosamente normado: el lenguaje composicional, traducido en la ordenación de los elementos -proporción de vanos y llenos, molduras, distanciamiento de pilastras y canterías- condicionó el resultado final. Entre las curiosidades de este megaproyecto estaba la relocalización del Congreso Nacional: se proponía al extremo sur del eje de la Avenida Bulnes, generando, así, una tensión con "la Moneda", nuestro Palacio de Gobierno.

Una talentosa generación de arquitectos fue haciendo realidad el proyecto del Barrio Cívico: Smith Solar y Smith Miller, de la Cruz y Rojas. Y otros posteriores, como Despouy, en 1950. La modernización de la cuadrícula central Santiago iba siendo respaldada por una arquitectura de gran coherencia y continuidad. 
http://revistaurbanismo.uchile.cl

Cabe destacar que algunas de las razones que explican la voluntad de remodelación urbana de Santiago se encuentran en la alta tasa de desempleo de ese momento, motivada por la brusca caída del precio del salitre y los efectos en Chile de la recesión mundial de 1929. Había, pues, que poner en marcha planes de largo aliento para absorber mano de obra desocupada. Fue el turno del Barrio Cívico, una intervención que integraba la casa de Gobierno, considerando el entorno en sus cuatro fachadas.

Muchas transformaciones se materializaron en torno al Palacio de Gobierno, del cual se había edificado, en 1927, la fachada sur, conforme al proyecto de J. Smith S.: se liberó una manzana para alojar allí la Plaza 5 de Septiembre, actualmente Plaza de la Constitución; hacia el sur del Palacio se propuso una plaza central, en mitad de la Alameda. Unos cuantos edificios en altura, limitando el extenso vacío, permiten que se destaque, merced a su condición de edificio aislado, La Moneda.

En el lapso de una década el sector adquirió su estatura definitiva, concentrando, en edificios de trece o más pisos, actividades habitacionales, de oficina y servicios de Gobierno.

Fueron, efectivamente, los llamados "edificios oficiales" los que dieron vida a los vacíos hacia el sur del Palacio de la Moneda, a la Plaza de la Libertad y a la Plaza Bulnes; hacia el norte, a la Plaza de la Constitución.

Entre los autores de estos inmuebles destacan Smith Solar y Smith Miller; René Aránguiz y Luis Muñoz, y C. Vera M. Los inmuebles se sucedieron en el siguiente orden cronológico: el edificio para el diario "La Nación", en 1929; el edificio, proyectado por el Arqto. R. Barceló, en calle Agustinas $N^{\circ} 1269$, en 1930. A continuación vinieron el de la Dirección de Correos y Telégrafos y, más adelante, el del Servicio de Seguro Social, proyectados por P. González y A. Fuentealba.

En 1929 y 1934 los arquitectos Smith Solar y Smith Miller proyectaron sendos edificios de trece pisos, que se destinaron a Ministerio de Hacienda y Hotel Carrera, respectivamente. Este último, funcionando hasta febrero de 2004 como hotel, para pasar a alojar, dentro de poco, la Cancillería de la República.

Otros edificios notables levantados en el sector céntrico fueron:

El edificio de renta de la Caja de Retiro y Montepío de la Defensa Nacional, de los Arqtos. F. de la Cruz y H. Rojas (1931), con diez pisos, en el borde oriente de la calle Teatinos, entre Agustinas y Huérfanos.

El edificio de nueve pisos, de los Arqtos. José Carlés y Guillermo Kaulen (1936), de nueve pisos, en la esquina noroeste de Agustinas y Morandé.

El conjunto de edificios de los Arqtos. Siegel y Siegel (1928-1935), en la manzana limitada por Huérfanos y Agustinas, Estado y Ahumada, de seis y siete niveles. 
http://revistaurbanismo.uchile.cl

El edificio Oberpaur de los arquitectos Arteaga y Larraín (1929-1932), en la esquina nororiente de Huérfanos y Estado, cuyas innovaciones anunciando el Movimiento Moderno se explican por la sabia utilización del hormigón armado.

El edificio de "Caja de Amortización", de H. Mardones, de nueve pisos, marca la altura de los edificios que se levantan más tarde en la calle Bandera.

El edificio de Ferrocarriles del Estado, de los Arqtos. Costabal, Garafulic y del Río (1934), donde actualmente se aloja el Ministerio de Vivienda y Urbanismo en la Avenida Libertador B. O'Higgins N0924.

Un edificio residencial de diez pisos de los Arqtos. Arteaga y Larraín (1934), en la esquina de las calles Santa Lucía y Merced.

No cabe duda que la atención a la condición sísmica del país ha contribuido al uso casi exclusivo del hormigón armado en los edificios de altura durante las primeras décadas del siglo XX.

Se agrega a ello otro hecho: en 1909 se instaló en Chile la primera fábrica de cemento (El Melón, La Calera). Ya no se siguió dependiendo para esto de los Estados Unidos. De esta forma, su uso, hasta entonces privativo de los estucos y morteros, se hizo extensivo a la construcción en general. En cambio, el acero chileno no estaba en condiciones de competir con el que en la época se importaba.

Señala Montserrat Palmer en su libro "50 años de arquitectura metálica en Chile 18631913":

..."el primer intento de instalar en Chile altos hornos es sólo de la primera década del siglo XX: los altos hornos de Corral, filial de la firma francesa Schneider y Co., Creusot, que los mantuvo en funcionamiento de 1910 a 1911 . Sólo en 1924 volvieron a trabajar con la formación de la "Compañía Electrosiderúrgica de Valdivia".

Cuando se construyeron los primeros edificios en altura -recordemos que el uso de las hormigoneras sólo se difundió a partir de 1930- no se sospechaba hasta qué punto la irrupción del hormigón armado habría de gravitar en las cualidades expresivas de la arquitectura. Al comienzo, la estructura se sobredimensionaba para no correr riesgos. Poco a poco se advirtió el cambio en las proporciones de los elementos soportantes y las ventajas de las plantas libres. Quienes primero se atrevieron a utilizar este nuevo material constructivo fueron los arquitectos familiarizados con él: Smith Solar (en contacto con la experiencia norteamericana), Siegel y Geiger (en contacto con la experiencia alemana), Cruz Montt, Larraín Bravo y Valdivieso (en contacto con la experiencia francesa).

La ordenanza que obligaba al uso de pilares y cadenas de hormigón armado en las construcciones de albañilería de ladrillos se promulgó después del terremoto que afectó, 
http://revistaurbanismo.uchile.cl

en 1928, a la zona central chilena. Poco después, en 1929 , se dictó la Ley $N^{\circ} 4563$, que reglamentó la construcción y la urbanización.

En general, los nuevos edificios, además de su altura, gozaron del privilegio de una localización protagónica: en una esquina o enfrente de una plaza. Casi siempre ocupaban la totalidad del predio, erigiéndose como cuerpos compactos, con perforaciones mesuradas para asegurar la prevalencia de los muros portantes.

La necesidad de iluminar y ventilar las habitaciones mediterráneas obliga a liberar algunos espacios intermedios, a manera de patios de luz.

La extensión de las fachadas propone un prolijo trabajo del estuco, valiéndose de relieves en distintos planos, así como también algunas líneas incisas verticales para demarcar los cuerpos que conforman la composición general. Una característica propia de estos edificios son los órdenes clásicos que se advierten en las fachadas, yendo de abajo hacia arriba: basamento o zócalo, un cuerpo central y un remate superior o coronación.

No es raro que en las esquinas los volúmenes se trabajen con planos curvos o bien con ochavos. Es el momento en que se suma a la tradición historicista una fuerte voluntad de cambio, la que se observa en el advenimiento del racionalismo. Los primeros acercamientos fueron mediante publicaciones extranjeras. Más adelante, a través de tímidos intentos materializados en la arquitectura pública.

No hay, sin embargo, una expresión única. En efecto, ésta depende del tipo de encargo y de la localización física. Conviven en esta época expresiones tan disímiles como los edificios racionalistas de la Plaza Constitución y las casas neogóticas de la calle Dieciocho. O la inspiración neoclásica en ciertos palacios de la aristocracia.

Los edificios en altura, destinados al comienzo a oficinas y servicios, se concentraron preferencialmente en el casco histórico. Su irrupción alteró en alguna medida el orden urbano existente: aparecen espacios públicos asociados y nuevas vías de circulación.

\section{El edificio de la ex Caja de Crédito Agrario}

En lo referido al edificio de la ex Caja de Crédito Agrario, localizada en Teatinos 10-20, este proyecto de 1939, de los arquitectos René Aránguiz Saravia y Luis Muñoz Maluschka, con la participación del Ingeniero Guillermo Franke, se desarrolla en ocho pisos de altura, en medio de una cuadra de construcción continua. Siete módulos iguales dividen el edificio en franjas verticales.

El primer piso, de doble altura, se constituye en el basamento del edificio y cuenta con dos accesos practicados en el segundo y sexto módulo. Entre ambos accesos, hay tres ventanas centrales. Los módulos extremos repiten las ventanas del centro. 
http://revistaurbanismo.uchile.cl

El tratamiento ortogonal de las fenestraciones se rompe únicamente en los accesos: sendos arcos de medio punto los señalan. Un cornisamento en sobrerrelieve define el cuerpo superior, que comprende una retícula de fenestraciones (siete filas por siete columnas). Cada fenestración consiste en una ventana con parteluz. Por lo tanto, si se quiere, pueden contarse 98 ventanas a partir de la imposta que separa el primero del segundo cuerpo.

Cabe destacar, por una parte, que algunos elementos de la arquitectura interior de este edificio presentan inspiración en el Art Deco, como es el caso de la geometrización del arranque del pasamano de la escala (Vid infra: fotografía en colección $b / n$ ). Por otra, que especialmente el espacio público del hall central de la obra en comento, realzado por la luz cenital de su lucernario, es de excepcional calidad.

El uso actual del edificio comprende diversas reparticiones públicas del Ministerio Secretaría General de Gobierno, Tesorería General de la República, Ministerio de Educación. Programa MECE y otras, y también dos pisos con actividades privadas. Esta situación, y la inexistencia de los planos originales en los archivos de OO.PP., hacen difícil una apreciación crítica del edificio. No obstante, un conjunto de fotografías de 1940 en blanco y negro, sumadas a algunas vistas propias que hemos realizado, permiten observar la calidad y riqueza de este caso de arquitectura racionalista organizada en banda continua en el marco del Barrio Cívico de Santiago.

(Vid infra: Galería fotográfica) 
A propósito de un edificio en el Barrio Cívico de Santiago de Chile:

La Ex Caja de Crédito Agrario.
A building in the Civic Center in Santiago, Chile: Former Caja Agraria

REVISTA DE

URBANISMO

ISSN $0717-5051$

http://revistaurbanismo.uchile.cl

\section{Índice Galería fotográfica}

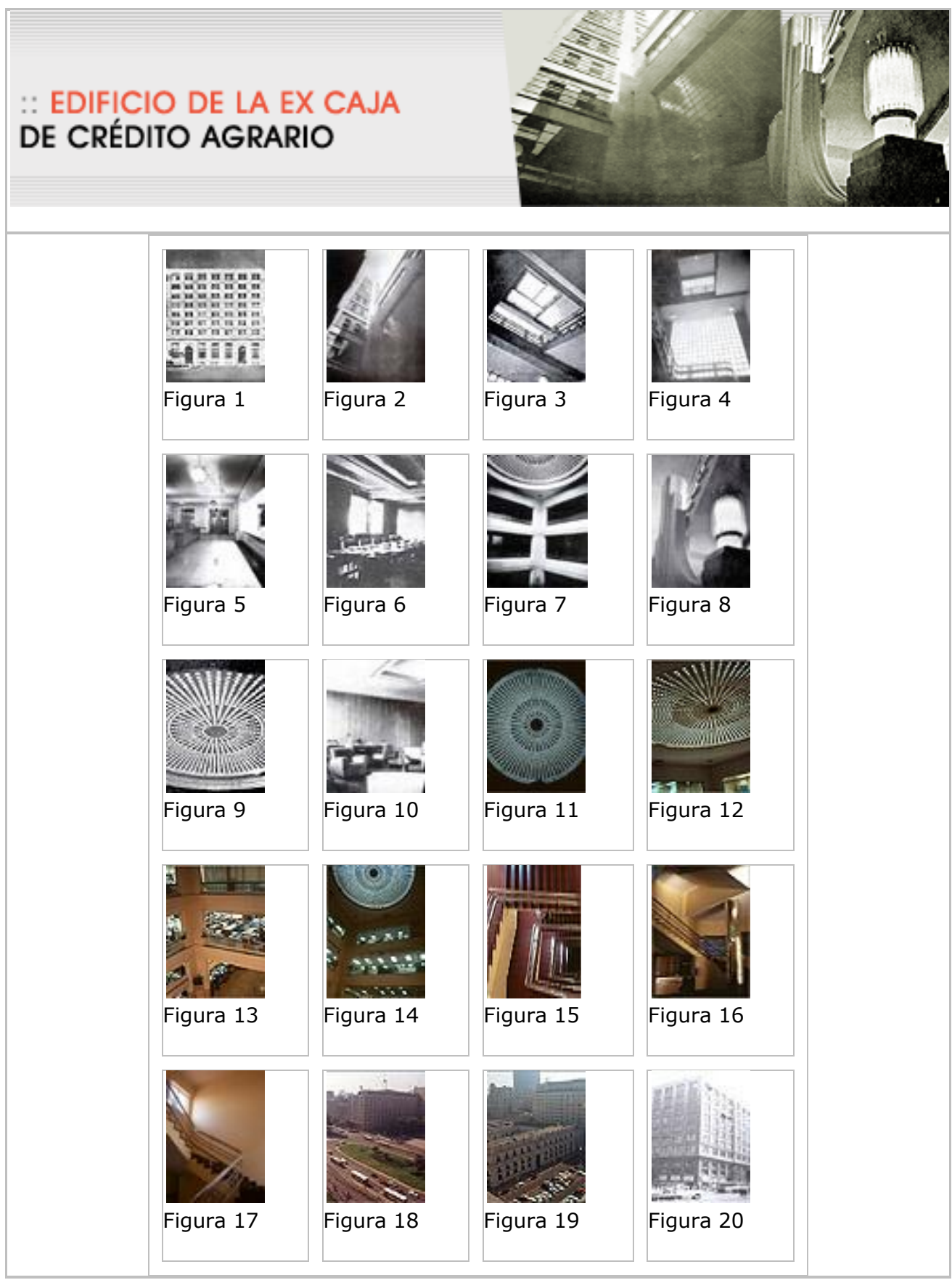




\section{REVISTA DE URBANISMO}

ISSN 0717-5051

http://revistaurbanismo.uchile.cl

Figuras 1.- y 2.-

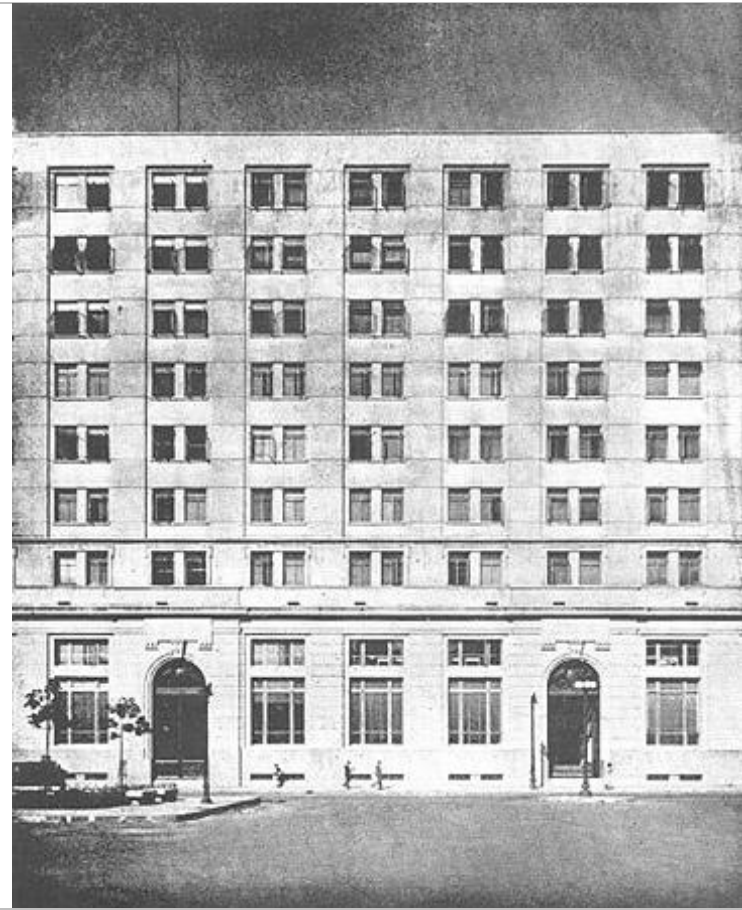

Figura1. Vista de la fachada principal del edificio de la ex Caja de Crédito Agrario, 1940.

Fuente: Revista Urbanismo y Arquitectura No9, 1940, Santiago de Chile, Órgano Oficial de la Asociación de Arquitectos de Chile, pp.4/446$26 / 468$.

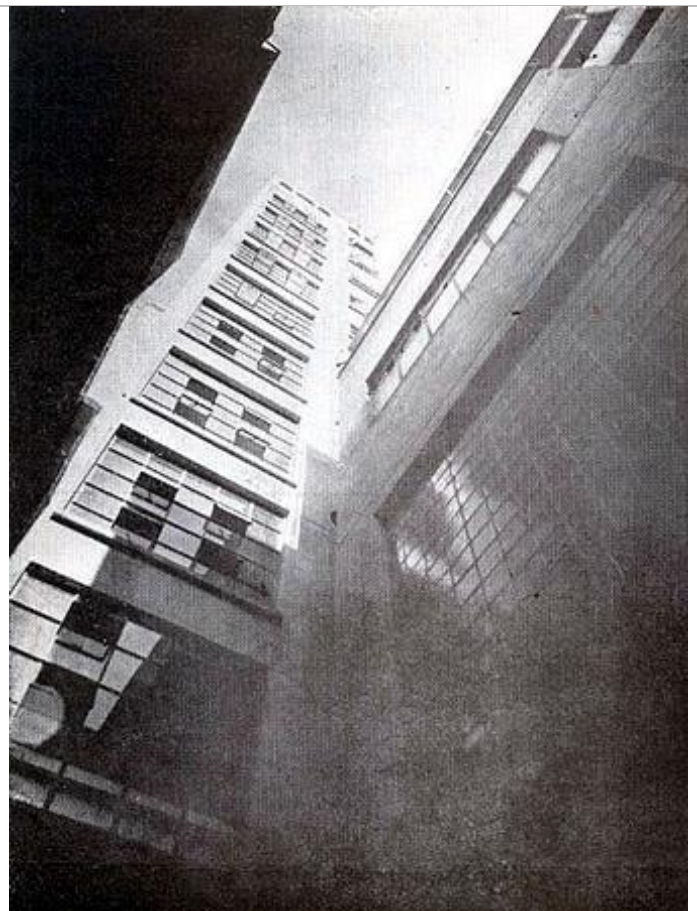

Figura2. Vista de fachada interior del edificio de la ex Caja de Crédito Agrario, 1940.

Fuente: Revista Urbanismo y Arquitectura No9, 1940, Santiago de Chile, Órgano Oficial de la Asociación de Arquitectos de Chile, pp.4/446-26/468. 
A propósito de un edificio en el Barrio Cívico de Santiago de Chile: La Ex Caja de Crédito Agrario.

\section{REVISTA DE URBANISMO}

ISSN 0717-5051

http://revistaurbanismo.uchile.cl

Figura 3.- y 4.-

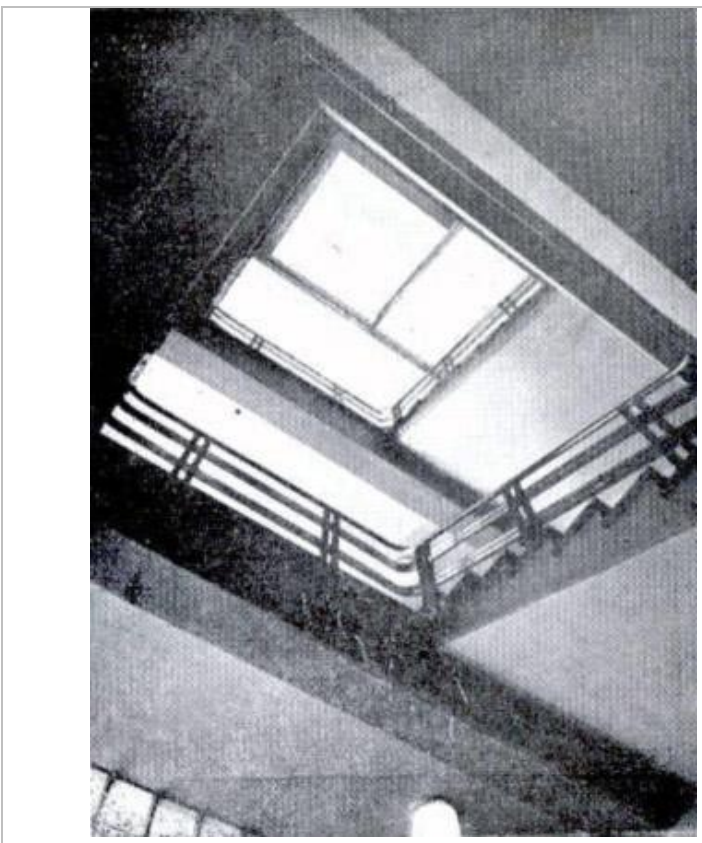

Figura 3.- Vista interior hacia niveles superiores de escalera del edificio de la ex Caja de Crédito Agrario, 1940.
Fuente: Revista Urbanismo y Arquitectura No9, 1940, Santiago de Chile, Órgano Oficial de la Asociación de Arquitectos de Chile, pp.4/446-26/468.

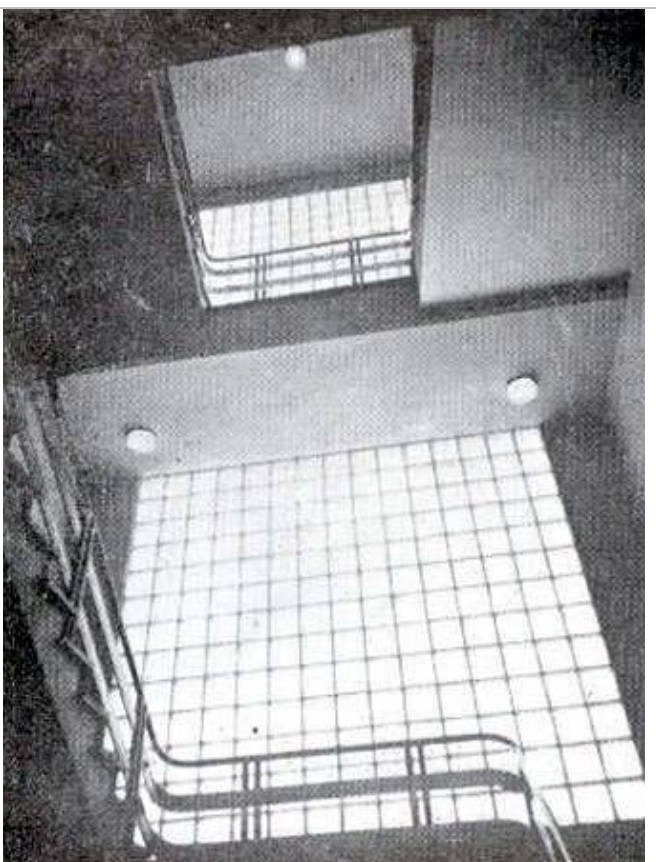

Figura 4.- Vista interior hacia niveles superiores de escalera del edificio de la ex Caja de Crédito Agrario, 1940.

Fuente: Revista Urbanismo y Arquitectura No9, 1940, Santiago de Chile, Órgano Oficial de la Asociación de Arquitectos de Chile, pp.4/446$26 / 468$ 


\section{REVISTA DE URBANISMO}

ISSN $0717-5051$

$h t p$ ://revistaurbanismo.uchile.cl

Figuras 5.- y 6.-

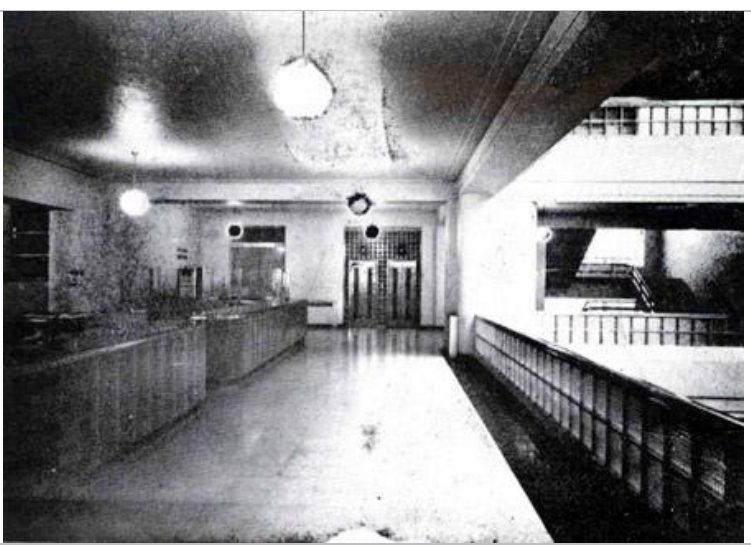

Figura5. Vista de área de trabajo junto a circulación en pisos superiores, con efecto de balcón sobre hall central del edificio de la ex Caja de Crédito Agrario, 1940.

Fuente: Revista Urbanismo y Arquitectura No9, 1940, Santiago de Chile, Órgano Oficial de la Asociación de Arquitectos de Chile, pp.4/446-26/468.

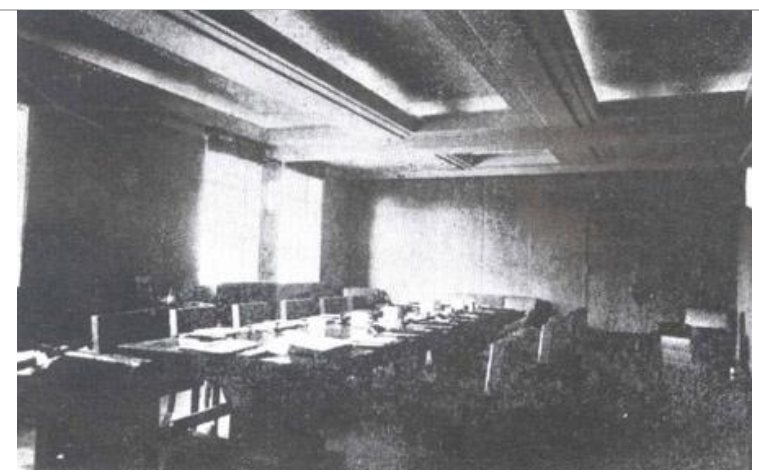

Figura6. Salón de reuniones en el edificio de la ex Caja de Crédito Agrario, 1940.

Fuente: Revista Urbanismo y Arquitectura No9, 1940, Santiago de Chile, Órgano Oficial de la Asociación de Arquitectos de Chile, pp.4/446-26/468. 


\section{REVISTA DE URBANISMO \\ ISSN 0717-5051}

http://revistaurbanismo.uchile.cl

Figuras 7.- y 8.-

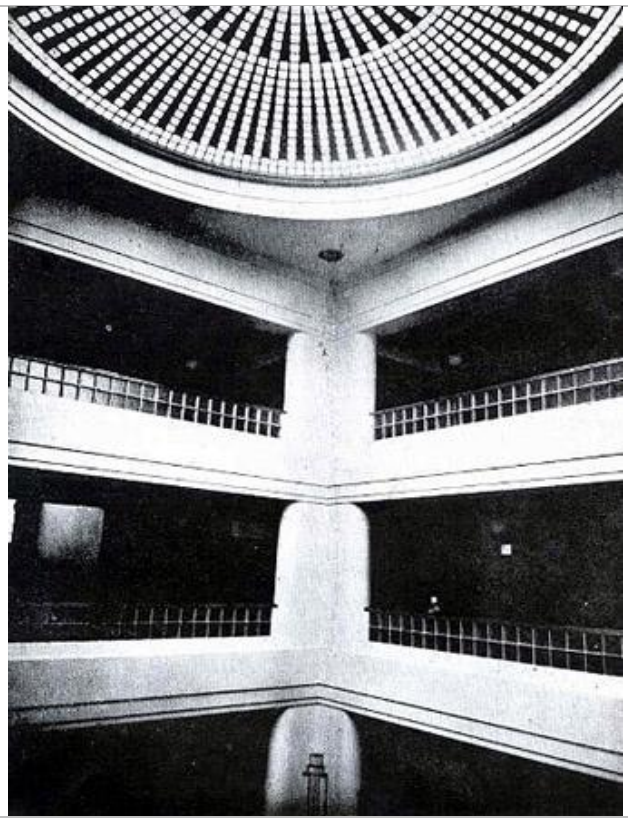

Figura 7.- Detalle del hall central realzado por la luz cenital de lucernario del edificio de la ex Caja de Crédito Agrario.

Fuente: Revista Urbanismo y Arquitectura No9, 1940, Santiago de Chile, Órgano Oficial de la Asociación de Arquitectos de Chile, pp.4/446-26/468.

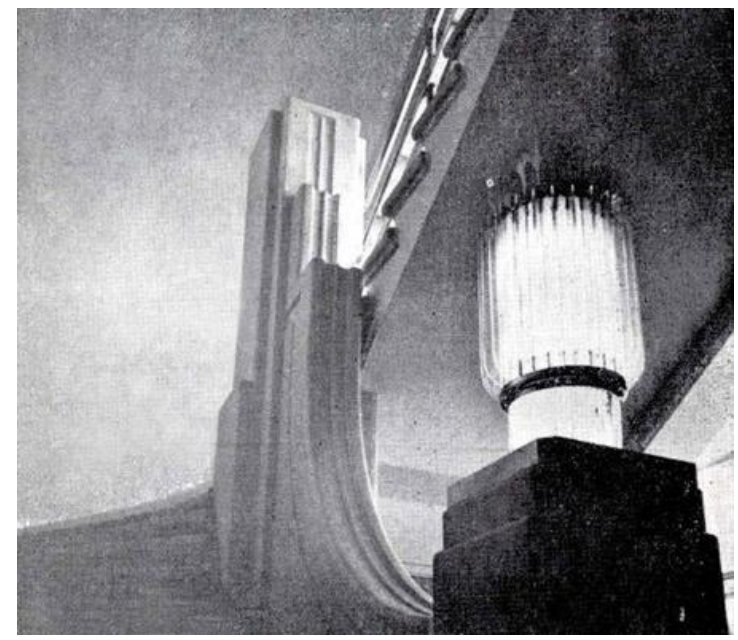

Figura 8.- Geometrización de inspiración Art Deco, del arranque del pasa mano de la escala del edificio de la ex Caja de Crédito Agrario, 1940.

Fuente: Revista Urbanismo y Arquitectura No9, 1940, Santiago de Chile, Órgano Oficial de la Asociación de Arquitectos de Chile, pp.4/446-26/468. 
A propósito de un edificio en el Barrio Cívico de Santiago de Chile:

La Ex Caja de Crédito Agrario.

\section{REVISTA DE URBANISMO}

ISSN $0717-5051$

$h t p$ ://revistaurbanismo.uchile.cl

Figuras 9.- y 10.-

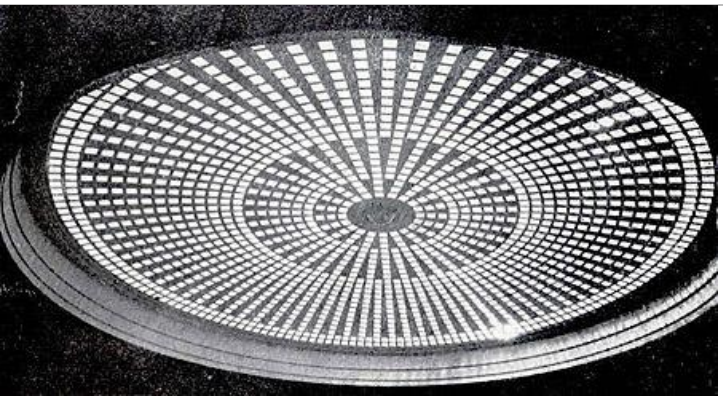

Figura9. Lucernario del edificio de la ex Caja de Crédito Agrario, 1940.

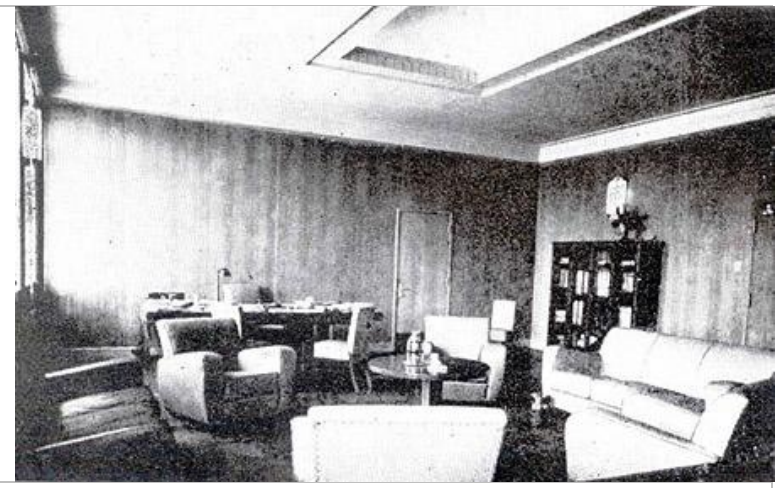

Figura10. Sala de estar del edificio de la ex Caja de Crédito Agrario, 1940.

Fuente: Revista Urbanismo y Arquitectura No9, 1940, Santiago de Chile, Órgano Oficial de la Asociación de Arquitectos de Chile, pp.4/446-26/468.

Fuente: Revista Urbanismo y Arquitectura No9, 1940, Santiago de Chile, Órgano Oficial de la Asociación de Arquitectos de Chile, pp.4/446-26/468. 
A propósito de un edificio en el Barrio Cívico de Santiago de Chile:

La Ex Caja de Crédito Agrario.

\section{REVISTA DE URBANISMO \\ ISSN $0717-5051$}

http://revistaurbanismo.uchile.cl

Figuras. 11.- y 12.-
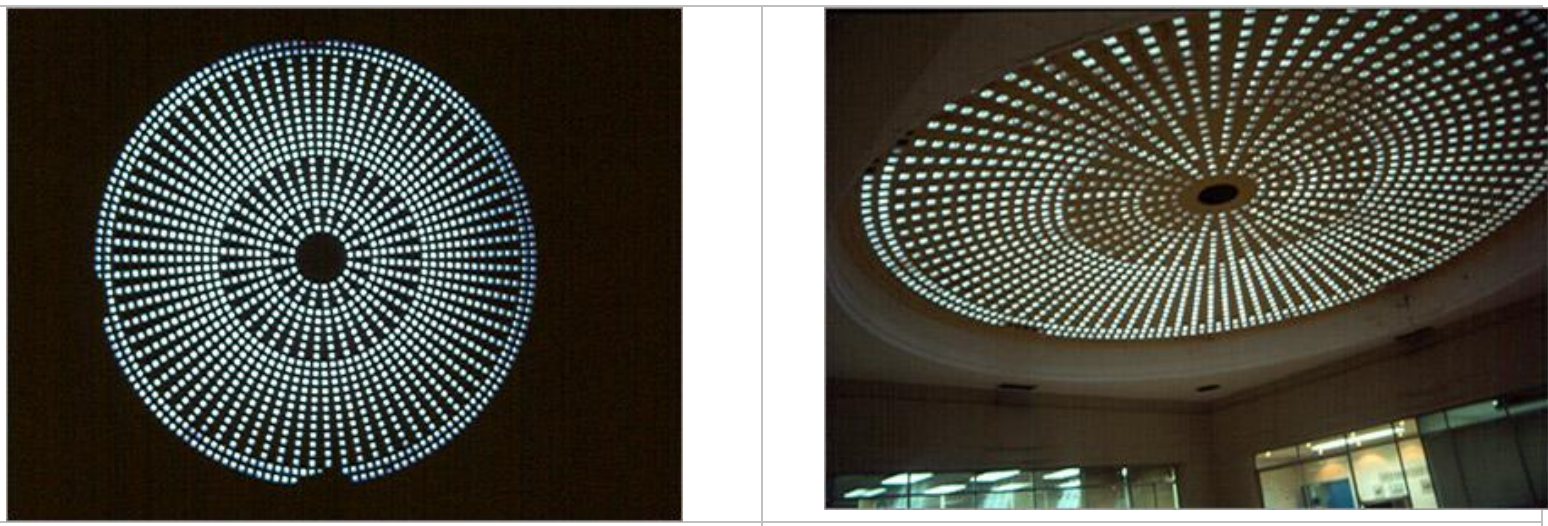

Figura11. Vista actual del lucernario del hall central del edificio de la ex Caja de Crédito Agrario.

Figura12. Vista actual del lucernario del hall central del edificio de la ex Caja de Crédito Agrario, desde el piso superior. 
A propósito de un edificio en el Barrio Cívico de Santiago de Chile:

\section{REVISTA DE URBANISMO}

ISSN 0717-5051

http://revistaurbanismo.uchile.cl

Figura 13.-

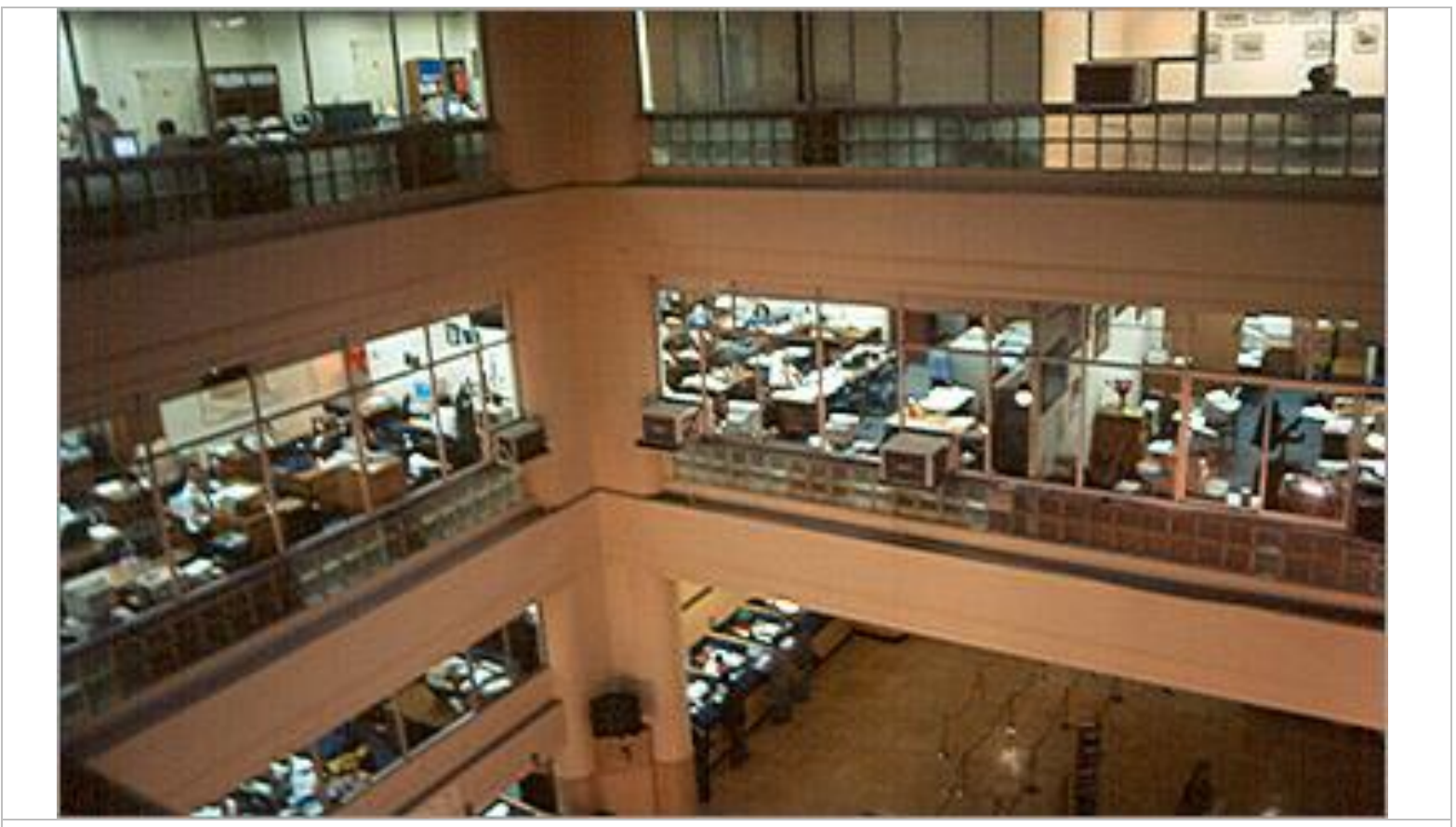

Figura13. Vista actual de zonas de trabajo en diversos pisos, donde se aprecia ocupación de áreas de circulación originales, y cerramiento del espacio en el plano perimetral del hall central. Edificio de la ex Caja de Crédito Agrario.

Fuente: fotografía de A. Sahady, 2003. (c) 
A propósito de un edificio en el Barrio Cívico de Santiago de Chile:

\section{REVISTA DE URBANISMO}

ISSN $0717-5051$

http://revistaurbanismo.uchile.cl

Figuras 14.- y 15.-

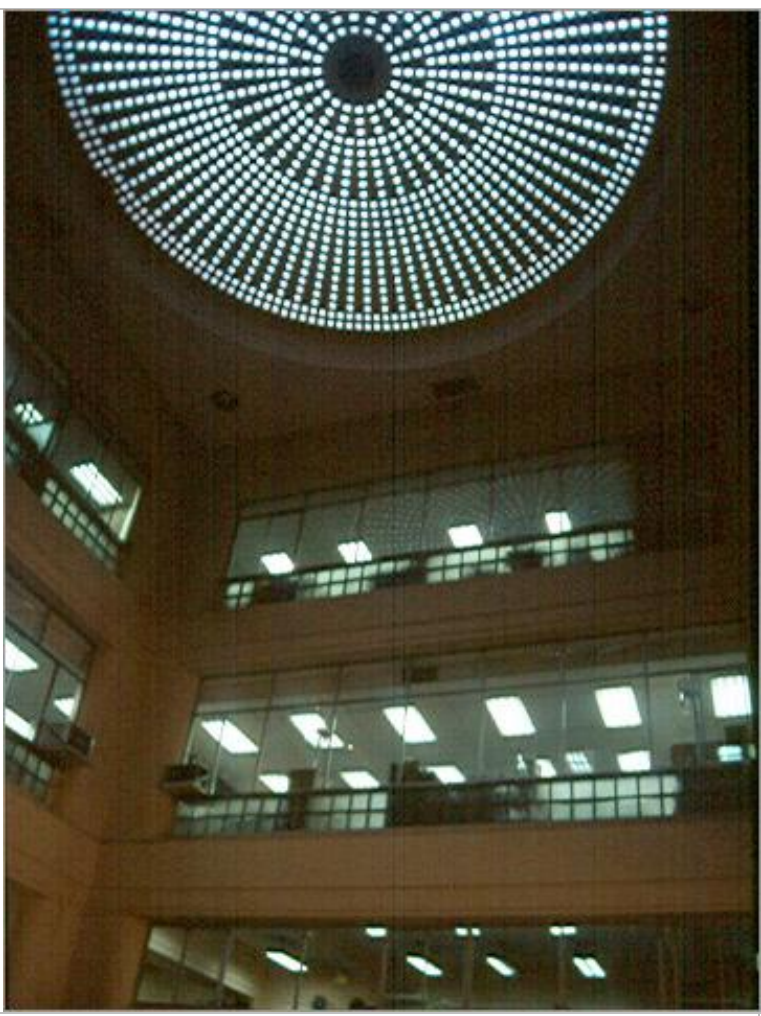

Figura14.- Vista actual de cielos y lucernarios desde el hall central del edificio de la ex Caja de Crédito Agrario.

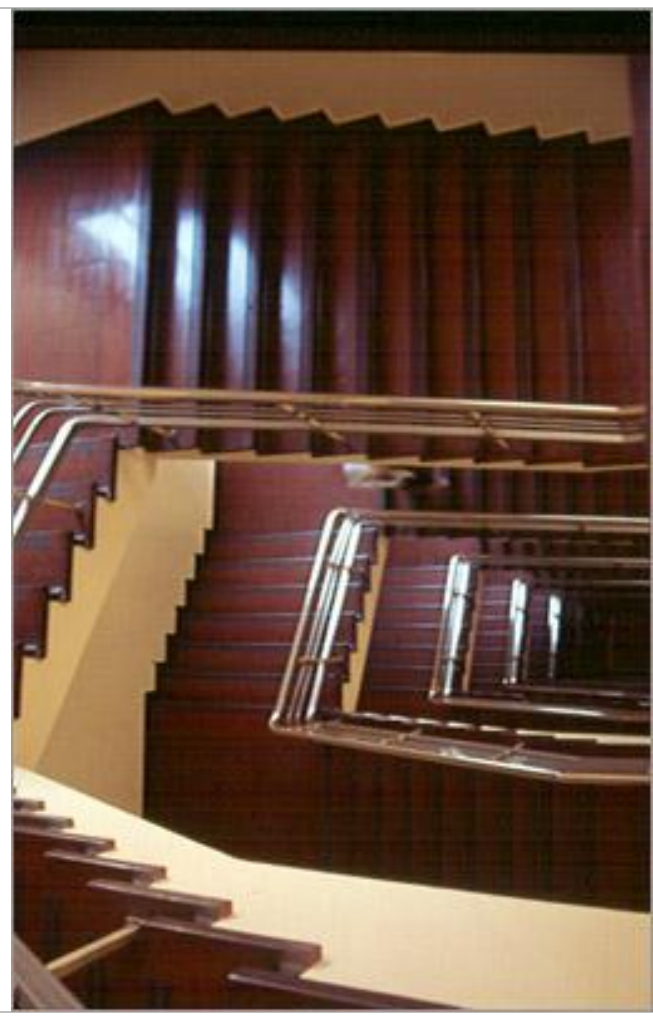

Figura15.- Vista del vacío central de escalera principal del edificio de la ex Caja de Crédito Agrario.

Fuente: fotografía de A. Sahady, 2003. (c) 
A propósito de un edificio en el Barrio Cívico de Santiago de Chile:

\section{REVISTA DE URBANISMO}

ISSN 0717-5051

http://revistaurbanismo.uchile.cl

Figuras 16.- y 17.-

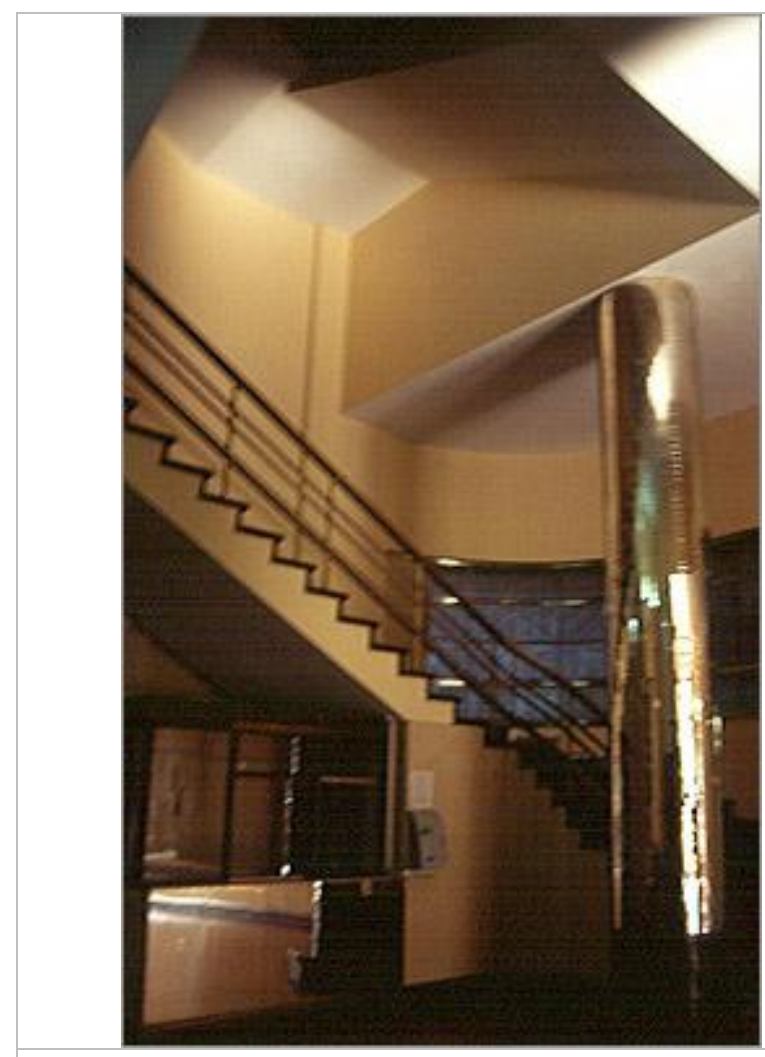

Figura16.- Vista de columna junto a escalera del edificio de la ex Caja de Crédito Agrario.

Fuente: fotografía de A. Sahady, 2003. @

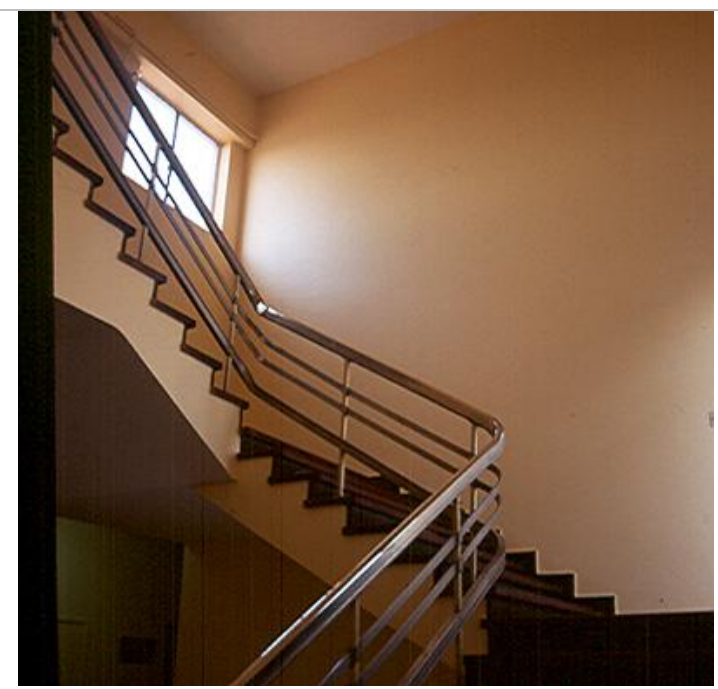

Figura17.- Iluminación natural en escalera. Edificio de la ex Caja de Crédito Agrario.

Fuente: fotografía de A. Sahady, 2003. @ 
A propósito de un edificio en el Barrio Cívico de Santiago de Chile:

La Ex Caja de Crédito Agrario.

\section{REVISTA DE URBANISMO}

ISSN 0717-5051

http://revistaurbanismo.uchile.cl

\section{Figura 18.-}

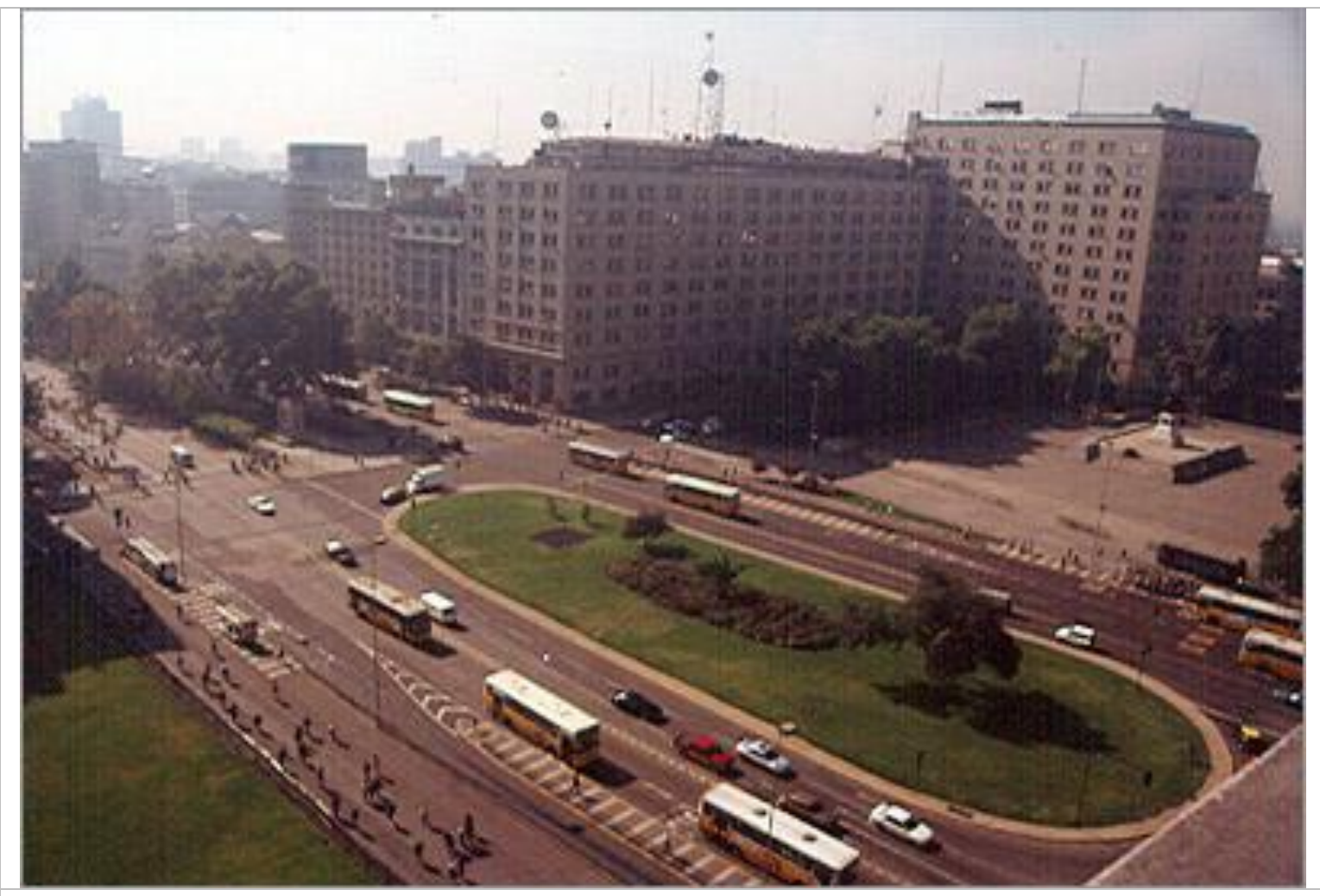

Figura18.- Vista hacia el sur oriente del Barrio Cívico desde la terraza del edificio de la ex Caja de Crédito Agrario.

Fuente: fotografía de A. Sahady, 2003. (c) 
A propósito de un edificio en el Barrio Cívico de Santiago de Chile: La Ex Caja de Crédito Agrario.

$\underset{I S S N}{\text { REVISTA D DE }}$

http://revistaurbanismo.uchile.cl

Figura 19.-

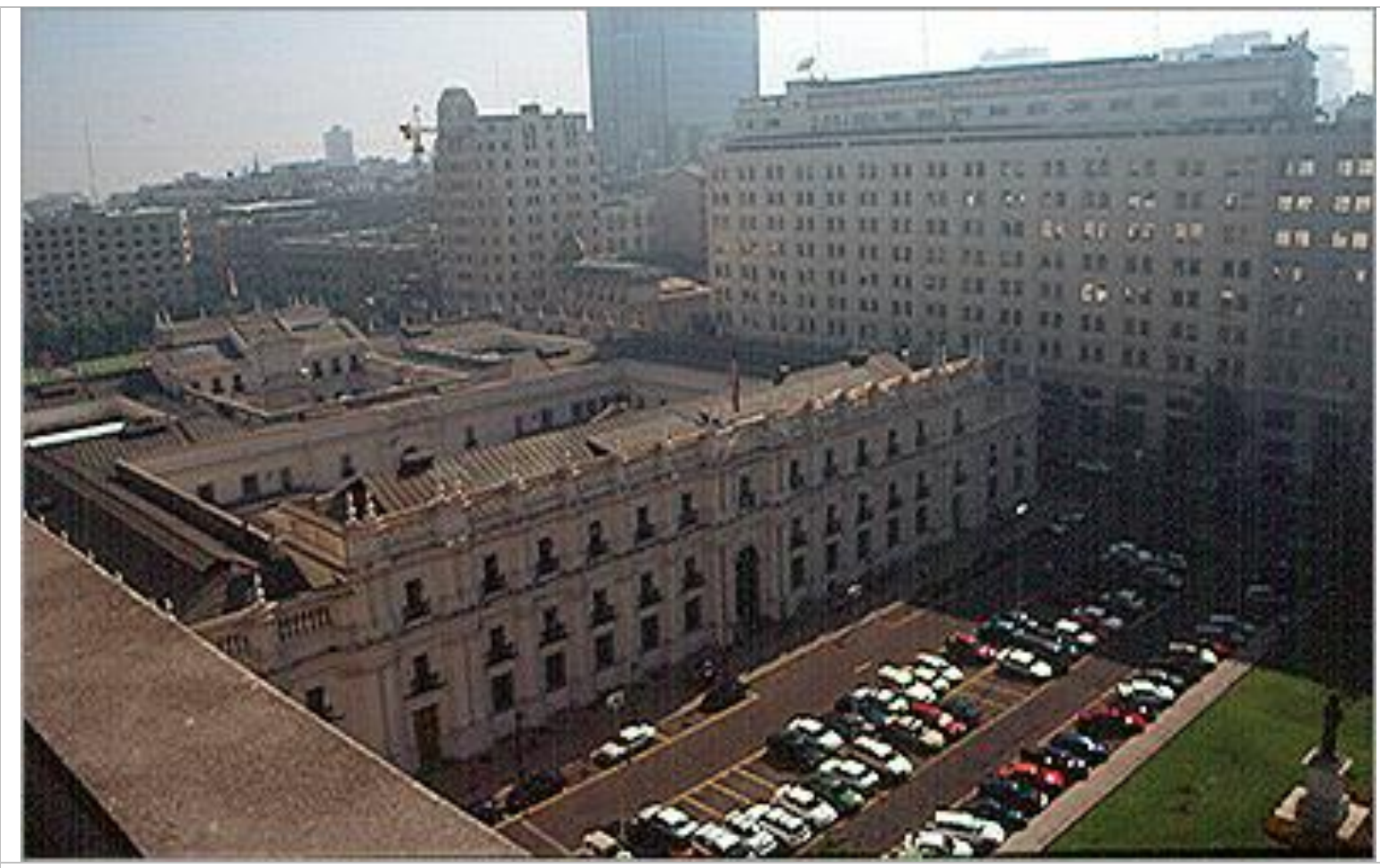

Figura19.- Vista hacia el nor oriente del Barrio Cívico, sobre el Palacio de Gobierno, La Moneda, desde la terraza del edificio de la ex Caja de Crédito Agrario.

Fuente: fotografía de A. Sahady, 2003. (c) 
A propósito de un edificio en el Barrio Cívico de Santiago de Chile: La Ex Caja de Crédito Agrario.

$\underset{I S S N \text { REVI7-5051 }}{\text { REVISTA DE }}$

http://revistaurbanismo.uchile.cl

Figura 20.-

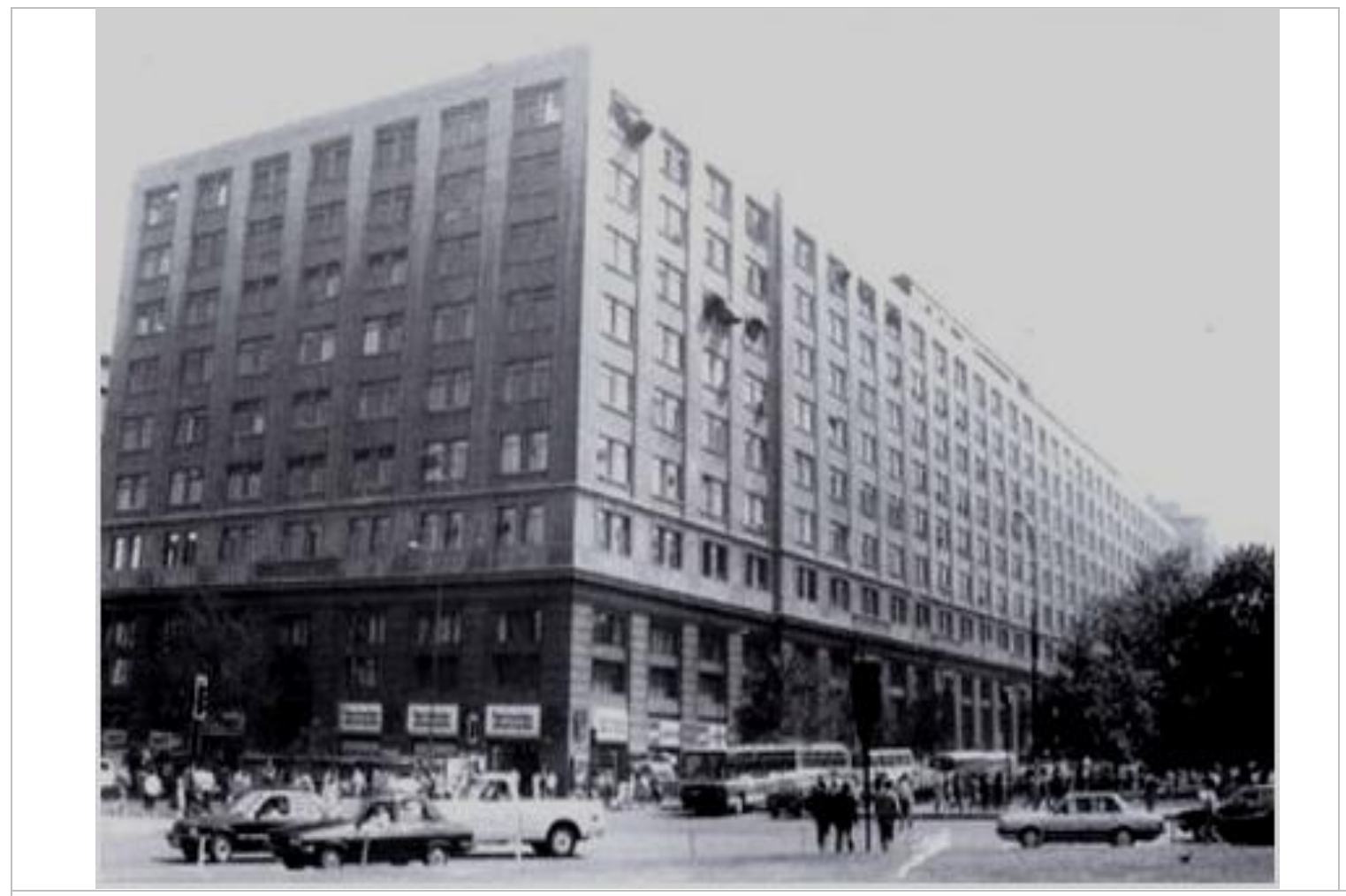

Figura20.- Vista del edificio del la ex Caja de Crédito Agrario, en el conjunto nor poniente del Barrio Cívico. El edificio de los arquitectos Muñoz y Aránguiz, corresponde al tercio central del bloque en la imagen.

Fuente: R. Chandía, 1991, Unidad de Fotografía, Universidad de Chile. 
http://revistaurbanismo.uchile.cl

\section{Bibliografía}

URBANISMO Y ARQUITECTURA $N^{\circ} 9$, Santiago, Órgano Oficial de la Asociación de Arquitectos de Chile, julio de 1940, pp.4/446 - 26/468.

ELIASH, Humberto y Manuel Moreno. Arquitectura y Modernidad en Chile / 1925-1965. Una realidad múltiple. Ediciones Universidad Católica de Chile. Serie Arte/ Arquitectura. Santiago, 1989, p. 106.

FIGUEROA SALAS, Jonás, "1929: la ciudad demostrativa", en: revista DE ARQUITECTURA N8, Especial Karl Brunner, Santiago de Chile, F.A.U., U. de Chile, 1996, pp. 4-7.

GUROVICH W., Alberto, "La solitaria estrella: en torno a la realización del Barrio Cívico de Santiago de Chile, 1846-1946", en: REVISTA DE URBANISMO N7, D. Urbanismo, F.A.U. U. CH., enero de 2003 [en línea] DOI: 10.5354/0717-5051.2003.6214 http://www.revistas.uchile.cl/index.php/RU/article/viewFile/6214/11830

LAMBERT, Jacques H., 1929 (o antes de marzo de 1930). "Notas sobre el informe preliminar del Plano de Santiago". En: ARQUITECTURA Y ARTE DECORATIVO, No9, Órgano oficial del Colegio de Arquitectos de Chile, Santiago de Chile, marzo de 1930, p. 396-397. [Traducido, o hecho traducir, por Ricardo González Cortés].

LAMBERT, Jacques H., 1929 (o antes de marzo de 1930). "Apuntes sobre Urbanismo". En: ARQUITECTURA Y ARTE DECORATIVO, No9, Órgano oficial del Colegio de Arquitectos de Chile, Santiago de Chile, marzo de 1930, p. 397-399. [Traducido, o hecho traducir, por Ricardo González Cortés].

LE CORBUSIER (1937, en París, C.I.A.M.). "Soluciones fundamentales propuestas al CIAM". En: Municipalidad de Santiago, BOLETÍN DE ESTADÍSTICA, IX-X, jul.-dic., 1938, pp.94-111.

LE CORBUSIER, Principios del Urbanismo (La Carta de Atenas), Barcelona, Editorial Ariel, Esplugues de Llobregat, 1971/73.

MARDONES OTAIZA, Francisco. 1934. Plano Regulador de Santiago. Nota del Ing. Francisco Mardones, Presidente de la Comisión del Plano Regulador de Santiago, al Sr. Alcalde de la I. Municipalidad. Imprenta Nascimiento, Santiago de Chile, 1934.

ORTEGA S., Oscar y Patricio Hermosilla G., "Introducción de la edificación en altura en Chile". En: Revista DE ARQUITECTURA N07. Facultad de Arquitectura y Urbanismo, Universidad de Chile. Santiago, Primer semestre de 1996, pp. 14-21.

PALMER TRIAS, Montserrat. 50 años de arquitectura metálica en Chile. 1863-1913. Instituto de Historia de Arquitectura, F.A.U. U. Chile, Santiago, 1970. 
http://revistaurbanismo.uchile.cl

PAVEZ REYES, M. Isabel, "Precursores de la enseñanza del Urbanismo en Chile 19281953", en: revista DE ARQUITECTURA N³, Facultad de Arquitectura y Urbanismo, Universidad de Chile, octubre de 1992, pp. 2-11.

PAVEZ REYES, M. Isabel (Investigadora Responsable); SAHADY VILLANUEVA, Antonio (Co-investigador), "Vertientes urbanísticas modernas en Chile 1928-1958: Conceptos de Vialidad y Transporte en los debates y estrategias de ordenación del territorio. Luis Muñoz Maluschka, un moderno reflexivo en el MOP", Informe final, Concurso F.A.U. de Proyectos de Investigación Arquitectura y Urbanismo, Geografía y Diseño 2002 (julio de 2002 - julio 2003), 244 págs. ilustradas.

[El presente artículo es un extracto de esta investigación].

URBANISMO Y ARQUITECTURA N09, 1940, pp. 463/21; 464/22: 465/23; 466/24; $467 / 25 ; 468 / 26$.

\section{Anexo: "La altura de los edificios" [1930]}

En: "El Diario Ilustrado", reproducido por Revista A. y A.D., en julio de 1930.

Se ha discutido últimamente en la prensa la cuestión de los rascacielos, sobre lo cual se han emitido las más variadas y contradictorias opiniones.

Quienes opinan que los rascacielos son un absurdo en ciudades como las nuestras, de edificación generalmente baja y expuesta a los fenómenos sísmicos, hay quienes sostienen que, por el contrario, los rascacielos son una manifestación de progreso y de vitalidad, un impulso hacia arriba de nuestros achatados conjuntos urbanos.

Cabe observar, desde luego, que en esta materia todos se han ido a los extremos: a la aprobación absoluta de la edificación alta, sin distinción de objeto ni de situación; o a su rechazo de plano, en toda la línea.

Entretanto, si hay algo en que el distingo se impone es en esta cuestión, sea que se la considere desde el punto de vista comercial; sea que se la mire por el lado estético, urbanístico o arquitectónico.

Comencemos por eliminar del tema la palabra rascacielo, expresión importada que difícilmente pueda tener aplicación entre nosotros. Los edificios de siete, ocho o diez pisos eran ya comunes en el mundo cuando aún a nadie se le había ocurrido que tales estructuras pudieran amenazar a las nubes. Sólo cuando el último precio del terreno en el barrio financiero de "Manhattan" obligó a buscar en la atmósfera la extensión que fallaba en el suelo -aprisionado entre las aguas de la bahía y de ambos ríos- sólo entonces surgió la imagen pintoresca encerrada en la palabra skyscraper, para calificar esos amontonamientos de oficinas comerciales que sobrepasan los veinte pisos. 
A propósito de un edificio en el Barrio Cívico de Santiago de Chile:

La Ex Caja de Crédito Agrario.
A building in the Civic Center in Santiago, Chile: Former Caja Agraria

REVISTA DE

http://revistaurbanismo.uchile.cl

Y el skycraper, que de Nueva York se extendió a los centros igualmente congestionados de otras ciudades norteamericanas, ha quedado en los Estados Unidos lo que fue en su origen: una estructura exclusivamente comercial, un edificio de oficinas, solución obligada para obtener del costo de un predio sobrevalorizado, siquiera un cuatro o cinco por ciento de interés.

El rascacielos -entiéndase edificio que excede los doce o quince pisos- no se construye por gusto en los Estados Unidos. Es hijo de la necesidad. No se admite, en general, en los barrios residenciales caracterizados en aquel país por la tendencia a la ciudad-jardín, con pequeños chalets o bungallows, de uno o dos pisos, semi ocultos entre el follaje.

No se usa allá, tampoco, el rascacielos para los edificios públicos, generalmente estructuras clásicas de muy pocos pisos. Tales son todos los de Washington y casi todos los de las otras capitales; aun en Nueva York, que no es cabecera de Estado sino ciudad esencialmente comercial, tenemos como ejemplo, el City Hall, o casa del Municipio, la Bolsa Comercial, la Clearing House, etc, edificios públicos que no pasan de los cuatro pisos.

Hemos tomado ejemplo sólo de los Estados Unidos, porque la edificación alta es esencialmente americana. En Europa no se justificaría por una apremiante necesidad financiera y se opondría, además, a la tradición inveterada.

En Chile, donde esa tradición no existe, y donde el problema del alto precio del suelo apenas si se presenta en uno que otro barrio de Santiago o de Valparaíso, podemos proceder con más libertad, atendiendo principalmente a los factores estéticos o urbanísticos.

En tal sentido, creemos que no es posible fijar normas absolutas o rígidas. La altura de los edificios debe depender de su objeto y de su ubicación. La edificación muy alta, que se justifica en los centros exclusivamente financieros, no parece natural en los barrios residenciales, ni mucho menos en los edificios públicos, que, por su naturaleza misma, deben poseer cierta nobleza o dignidad, incompatible con las líneas escuetas de la estructura comercial.

La altura de los edificios debe guardar también cierta relación con el ancho de las calles o con la magnitud de los espacios libres. En calles de diez o doce metros de ancho vienen mal los inmuebles de más de tres pisos. En cambio, estos mismos edificios -los que no pasan de tres pisos- se ven aplastados y pobres en grandes avenidas de ochenta o cien metros, como nuestra Alameda.

En grandes plazas o espacios abiertos no vienen mal los edificios muy altos, siempre que guarden cierta simetría con el conjunto, ubicándose en las cabeceras, el centro de las manzanas o donde formen pendant con otros de la misma estatura. Por falta de estas condiciones, no contribuirán a la belleza del conjunto, en el Barrio Cívico, algunas estructuras de la calle de Agustinas y de la Plazuela de la Moneda.

En esto de la edificación, como en todo, conviene eliminar las teorías exageradas y aplicar la sabia máxima de los romanos: "in medio stat virtus". 